\title{
Pemetrexed in maintenance treatment of advanced non-squamous non-small-cell lung cancer
}

\author{
This article was published in the following Dove Press journal: \\ Lung Cancer:Targets and Therapy \\ 29 January 2015 \\ Number of times this article has been viewed
}

\author{
Seigo Minami ${ }^{1}$ \\ Takashi Kijima ${ }^{2}$ \\ 'Department of Respiratory Medicine, \\ Osaka Police Hospital, ${ }^{2}$ Department \\ of Respiratory Medicine, Allergy and \\ Rheumatic Diseases, Osaka University \\ Graduate School of Medicine, Osaka, \\ Japan
}

Abstract: Pemetrexed, a multitargeting antifolate cytotoxic drug, plays a leading role in front-line chemotherapy for patients with advanced non-squamous non-small-cell lung cancer (NSCLC). Following its approval as second-line monotherapy for locally advanced or metastatic non-squamous NSCLC, pemetrexed has established itself as the first-line regimen in combination with cisplatin, and its powerful antitumor effects and less cumulative toxicities were then taken advantage of in the JMEN and PARAMOUNT trials, respectively, to pioneer a new treatment strategy of switch and continuation maintenance monotherapy. These developments have brought about a marked paradigm shift, and made pemetrexed indispensable in the treatment for non-squamous NSCLC. So far, only three drugs have been approved for maintenance therapy; pemetrexed both by switch and continuation maintenance, erlotinib by switch maintenance, and bevacizumab by continuation maintenance. Compared with observation alone after defined cycles of the first-line chemotherapy, subsequent pemetrexed maintenance therapy has provided significantly longer survival and infrequent severe adverse events. The cost-effectiveness of pemetrexed maintenance therapy is controversial, as well as the other two maintenance drugs, bevacizumab and erlotinib. The latest attractive attention is a combination maintenance therapy. We may have to consider epidermal growth factor receptor (EGFR) mutation status for selection of a combination pattern. A combination maintenance therapy of pemetrexed plus bevacizumab is potential for patients with wild-type EGFR status, while a EGFR tyrosine kinase inhibitorcontaining combination is promising for patients with active EGFR mutation status. Pemetrexed will be a pivotal drug when a combination maintenance therapy is used in practice. For future maintenance therapy, we need to explore reliable predictive selection or exclusion markers that can predict who will really benefit from maintenance therapy.

Keywords: pemetrexed, maintenance therapy, continuation, switch, non-squamous non-small cell carcinoma, cost-effectiveness, epidermal growth factor mutation

\section{Introduction}

Lung cancer is a leading cause of cancer mortality and accounted for 1.59 deaths worldwide in $2012 .{ }^{1}$ Histopathologically, lung cancer is divided broadly into two groups, ie, non-small-cell lung cancer (NSCLC) and small cell lung cancer. The former accounts for $80 \%-85 \%$ of all lung cancer cases, and is further divided into several subgroups, ie, adenocarcinoma, squamous cell carcinoma, large cell carcinoma, and others. Most patients with NSCLC are diagnosed when their disease has already advanced locally or metastasized systemically. For inoperable patients with good performance status, chemotherapy is a standard treatment option.

Pemetrexed (Alimta ${ }^{\circledR}$, Eli Lilly, Indianapolis, IN, USA) is a multitargeted antifolate drug that inhibits replication and survival of cancer cells by disrupting folate-dependent 
metabolic processes. During the past decade, this drug has come to have a leading role in front-line chemotherapy for patients with advanced non-squamous NSCLC, owing to its antitumor effects and mild toxicity.

When combined with platinum in a first-line regimen for non-squamous NSCLC, pemetrexed is superior or similar in efficacy and superior in toxicities to other third-generation antitumor drugs. There were three randomized Phase III studies that compared various endpoints between platinum plus pemetrexed and conventional platinum-based doublets in NSCLC (Table 1). ${ }^{2-4}$ Among them, a milestone was the JMDB trial, ${ }^{4}$ in which cisplatin plus pemetrexed showed noninferiority in overall survival (OS) and better tolerability compared with cisplatin plus gemcitabine. In addition, this trial also indicated a histological difference in efficacy. Namely, pemetrexed improved OS for patients with non-squamous histology, but failed for patients with squamous histology. These results led to the approval of cisplatin plus pemetrexed for patients with advanced non-squamous NSCLC as a first-line regimen by the European Medicines Agency in April 2008 and by the US Food and Drug Administration in September 2008. Health-related quality of life and survival without grade 3 or 4 toxicity (SWT) was compared between carboplatin plus pemetrexed and carboplatin plus gemcitabine in a Norwegian study and between carboplatin plus pemetrexed and carboplatin plus docetaxel in a multinational study, respectively. ${ }^{2,3}$ Compared with control regimens, carboplatin plus pemetrexed provided similar health-related quality of life and OS in the Norwegian study, ${ }^{2}$ and longer SWT but similar OS in the other study. ${ }^{3}$ In addition, platinum plus pemetrexed was generally less toxic, except for severe nausea, ${ }^{4}$ and generally caused less frequent severe leukopenia and neutropenia than control regimens in all studies (Table 2). ${ }^{2-4}$

Concerning cost-effectiveness, the platinum plus pemetrexed doublet is considered to be cost-effective, particularly in patients with non-squamous NSCLC histology (Table 3). There were two US studies with different approaches for first-line platinum plus pemetrexed. ${ }^{5,6}$ Based on a state transition model, Klein et al concluded that cisplatin plus pemetrexed was a cost-effective treatment for patients with non-squamous NSCLC when compared with cisplatin plus gemcitabine and a commonly mentioned but unwarranted threshold of US \$100,000 per life-year gained (LYG) in the USA. ${ }^{5}$ Compared with a first-line combination of cisplatin plus gemcitabine, cisplatin plus pemetrexed led to an incremental cost per LYG of US $\$ 104,577$ for patients with NSCLC regardless of histological subtype, but a cost of US $\$ 83,537$ for patients with non-squamous NSCLC.

Table I Phase III studies of combinations of pemetrexed plus platinum compared with standard platinum-based doublets

\begin{tabular}{|c|c|c|c|c|c|c|c|c|}
\hline Reference & $\begin{array}{l}\text { Primary } \\
\text { endpoint }\end{array}$ & $\mathbf{n}$ & Regimens & $\begin{array}{l}\mathbf{R R} \\
\text { (\%) }\end{array}$ & $\begin{array}{l}\text { PFS } \\
\text { (M) }\end{array}$ & $\begin{array}{l}\text { HR } \\
P \text {-value }\end{array}$ & $\begin{array}{l}\text { OS } \\
\text { (M) }\end{array}$ & $\begin{array}{l}\text { HR } \\
P \text {-value }\end{array}$ \\
\hline Scagliottii et al ${ }^{4}$ & $\mathrm{OS}^{a}$ & All $\mathrm{N}$ & , entire population & & & & & \\
\hline \multirow[t]{5}{*}{ (JMDB trial) } & & 862 & CDDP + PEM & 30.6 & 4.8 & HR I.04 & 10.3 & HR 0.94 \\
\hline & & 863 & $\begin{array}{l}\text { CDDP + GEM } \\
\times 6 \text { cycles }\end{array}$ & 28.2 & 5.1 & Non-inferior & 10.3 & $\begin{array}{l}\text { Non- } \\
\text { inferior }\end{array}$ \\
\hline & & Non & JSCLC subgroup & & & & & \\
\hline & & 512 & CDDP + PEM & ND & 5.3 & HR 0.90 & 11.8 & HR 0.8I \\
\hline & & 488 & CDDP + GEM & ND & 4.7 & ND & 10.4 & $P=0.005$ \\
\hline \multirow[t]{7}{*}{ Grønberg et $\mathrm{al}^{2}$} & HRQoL ${ }^{b}$ & All $N$ & , entire population & & & & & \\
\hline & & 225 & $\mathrm{CBDCA}+\mathrm{PEM}$ & ND & ND & ND & 7.3 & HR ND \\
\hline & & 221 & CBDCA + GEM & ND & ND & ND & 7.0 & $P=0.63$ \\
\hline & & & $\times 4$ cycles & & & & & \\
\hline & & Non & JSCLC subgroup & & & & & \\
\hline & & 127 & CBDCA + PEM & ND & ND & ND & 7.8 & HR ND \\
\hline & & 121 & $\mathrm{CBDCA}+\mathrm{GEM}$ & ND & ND & ND & 7.5 & $P=0.77$ \\
\hline Rodrigues- & SWT & All $n$ & 2 NSCLC & & & & & \\
\hline \multirow[t]{6}{*}{ Pereira et a $\left.\right|^{3}$} & & 128 & CBDCA + PEM & 34.0 & 5.8 & HR 0.9I & 14.9 & HR 0.93 \\
\hline & & 132 & CBDCA + DTX & 22.9 & 6.0 & $P=0.534$ & 14.7 & $P=0.698$ \\
\hline & & & $\times 6$ cycles & & & & & \\
\hline & & & & & & & SWT & \\
\hline & & 128 & CBDCA + PEM & & & & 3.2 & HR 0.45 \\
\hline & & 132 & $\mathrm{CBDCA}+\mathrm{DTX}$ & & & & 0.7 & $P<0.00$ I \\
\hline
\end{tabular}

Notes: ${ }^{a}$ Non-inferiority design; befined as the four clinically relevant domains of global quality of life, nausea/vomiting, dyspnea and fatigue, and assessed by the European Organisation for Research and Treatment of Cancer Quality of Life Questionnaire C30 (QLQ-C30) and the lung cancer-specific module LCI3 during the first 20 weeks. Abbreviations: CBDCA, carboplatin; CDDP, cisplatin; DTX, docetaxel; GEM, gemcitabine; HR, hazard ratio; HRQoL, health-related quality of life; M, months; ND, not described; RR, response rate; OS, overall survival; PEM, pemetrexed; PFS, progression-free survival; SQ, squamous cell carcinoma; SWT, survival without treatment-emergent grade $3 / 4$ toxicity. 
Table 2 Comparison of statistically significant adverse effects between pemetrexed-containing and control regimens

\begin{tabular}{|c|c|c|c|c|c|c|}
\hline \multirow{2}{*}{$\begin{array}{l}\text { Reference } \\
\text { Regimens }\end{array}$} & \multicolumn{2}{|c|}{$\begin{array}{l}\text { Scagliotti et } \text { al }^{4} \\
\text { (JMDB trial) }\end{array}$} & \multicolumn{2}{|c|}{ Grønberg et $\mathrm{al}^{2}$} & \multicolumn{2}{|c|}{ Rodrigues-Pereira et $\mathrm{al}^{3}$} \\
\hline & $\begin{array}{l}\text { CDDP + } \\
\text { PEM }\end{array}$ & $\begin{array}{l}\text { CDDP + } \\
\text { GEM }\end{array}$ & $\begin{array}{l}\text { CBDCA + } \\
\text { PEM }\end{array}$ & $\begin{array}{l}\text { CBDCA + } \\
\text { GEM }\end{array}$ & $\begin{array}{l}\text { CBDCA + } \\
\text { PEM }\end{array}$ & $\begin{array}{l}\text { CBDCA + } \\
\text { DTX }\end{array}$ \\
\hline $\mathrm{n}$ & 839 & 830 & 219 & 217 & 106 & 105 \\
\hline \multicolumn{7}{|l|}{ Hematologic } \\
\hline Leukopenia, grade 3-4 (\%) & $4.8^{\mathrm{a}}$ & 7.6 & $23^{\mathrm{a}}$ & 46 & $16.0^{\mathrm{a}}$ & 40.0 \\
\hline Neutropenia, grade 3-4 (\%) & $15.1^{\mathrm{a}}$ & 26.7 & $40^{\mathrm{a}}$ & 51 & $33.0^{\mathrm{a}}$ & 64.8 \\
\hline Anemia, grade $3-4(\%)$ & $5.6^{\mathrm{a}}$ & 9.9 & 13 & 13 & $12.3^{\mathrm{a}}$ & 1.9 \\
\hline Thrombocytopenia, grade 3-4 (\%) & 4. $1^{\mathrm{a}}$ & 12.7 & $24^{\mathrm{a}}$ & 56 & 9.4 & 2.9 \\
\hline \multicolumn{7}{|l|}{ Non-hematologic } \\
\hline Febrile neutropenia, grade 3-4 (\%) & $1.3^{\mathrm{a}}$ & 3.7 & ND & ND & $0^{\mathrm{a}}$ & 8.9 \\
\hline Alopecia, any grade (\%) & $11.9^{a}$ & 21.4 & ND & ND & $8.5^{\mathrm{a}}$ & 42.9 \\
\hline Nausea, grade 3-4 (\%) & $7.2^{\mathrm{a}}$ & 3.9 & 3 & 4 & 0.9 & 1.0 \\
\hline Diarrhea, any grade (\%) & ND & ND & ND & ND & $6.6^{a}$ & 20.0 \\
\hline Abdominal pain, any grade (\%) & ND & ND & ND & ND & $1.9^{\mathrm{a}}$ & 9.5 \\
\hline
\end{tabular}

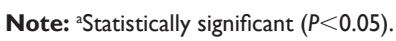

Abbreviations: CBDCA, carboplatin; CDDP, cisplatin; DTX, docetaxel; GEM, gemcitabine; ND, not described; PEM, pemetrexed.

Thus, considering the effect of prolongation of survival by the pemetrexed-containing regimen, pemetrexed was expensive but within the allowance. Based on indirect comparisons of the following three regimens in different studies because of no available head-to-head data, platinum plus pemetrexed was also considered more cost-effective than a triplet of bevacizumab combined with carboplatin plus paclitaxel, but controversial when compared with a doublet of carboplatin plus paclitaxel, as the pemetrexedcontaining regimen was more costly but more effective than carboplatin plus paclitaxel. ${ }^{5,6}$ In September 2009, the National Institute for Health and Clinical Excellence (NICE) in the UK recommended pemetrexed in combination with cisplatin as an option for the first-line treatment of patients with non-squamous NSCLC, using the single technology appraisal process and based on the Evidence Review Group's exploratory analysis indicating that the incremental costeffectiveness ratios (ICERs) for cisplatin plus pemetrexed compared with cisplatin plus gemcitabine were between $£ 20,000$ and $£ 30,000$ per quality-adjusted life-year (QALY) gained for non-squamous NSCLC and between $£ 17,000$ and $£ 25,000$ per QALY for adenocarcinoma or large-cell carcinoma, all under the willing-to-pay threshold of $£ 30,000$ per QALY gained. ${ }^{7}$

\section{Options for maintenance therapy; continuation maintenance versus switch maintenance}

Maintenance therapy after 4-6 cycles of platinum-based induction chemotherapy is a standard first-line regimen for patients with advanced non-squamous NSCLC. Maintenance therapies are classified broadly into two types, ie, continuation maintenance and switch maintenance. The former is a continuation of one or two drugs used in the induction regimen and the latter involves introduction of an additional drug that was not used in the induction regimen. Switch maintenance can be understood as an early second-line therapy. Differences in efficacy between these two maintenance strategies remain unknown. A recent metaanalysis did not detect any significant differences in OS or progression-free survival (PFS) between these two maintenance strategies. ${ }^{8}$ In contrast, another two meta-analyses showed favorable OS benefits for switch maintenance. ${ }^{9,10}$ In the study by Behera et al, switch maintenance provided significant benefit, both in PFS (hazard ratio [HR] 0.62, 95\% confidence interval $[\mathrm{CI}] 0.57-0.67, P<0.0001)$ and OS (HR 0.84, 95\% CI 0.77-0.91, $P=0.00026$ ). In contrast, continuation maintenance modestly improved PFS (HR $0.90,95 \%$ CI $0.85-0.95, P=0.007$ ), but did not show an OS benefit (HR $0.927,95 \%$ CI $0.78-1.09, P=0.33$ ). ${ }^{9}$ In the study by Cai et al, PFS was prolonged by both continuation (HR 0.54, 95\% CI 0.46-0.63, $P<0.00001$ ) and switch (HR $0.64,95 \%$ CI $0.59-0.70, P<0.00001)$ maintenance. Switch maintenance significantly improved OS (HR $0.80,95 \% \mathrm{CI}$ $0.72-0.90, P=0.0002$ ), while continuation maintenance did not achieve a statistically significant improvement (HR 0.82 , 95\% CI 0.66-1.01, $P=0.06) .{ }^{10}$ From the viewpoint of clinical practice, these two maintenance strategies are very different, especially at the time of transition from the induction phase to the maintenance phase. Most oncologists would hesitate to discontinue an effective and tolerable induction regimen and then introduce a new drug with unknown efficacy and adverse effects. Thus, continuation maintenance is more acceptable than switch maintenance. 


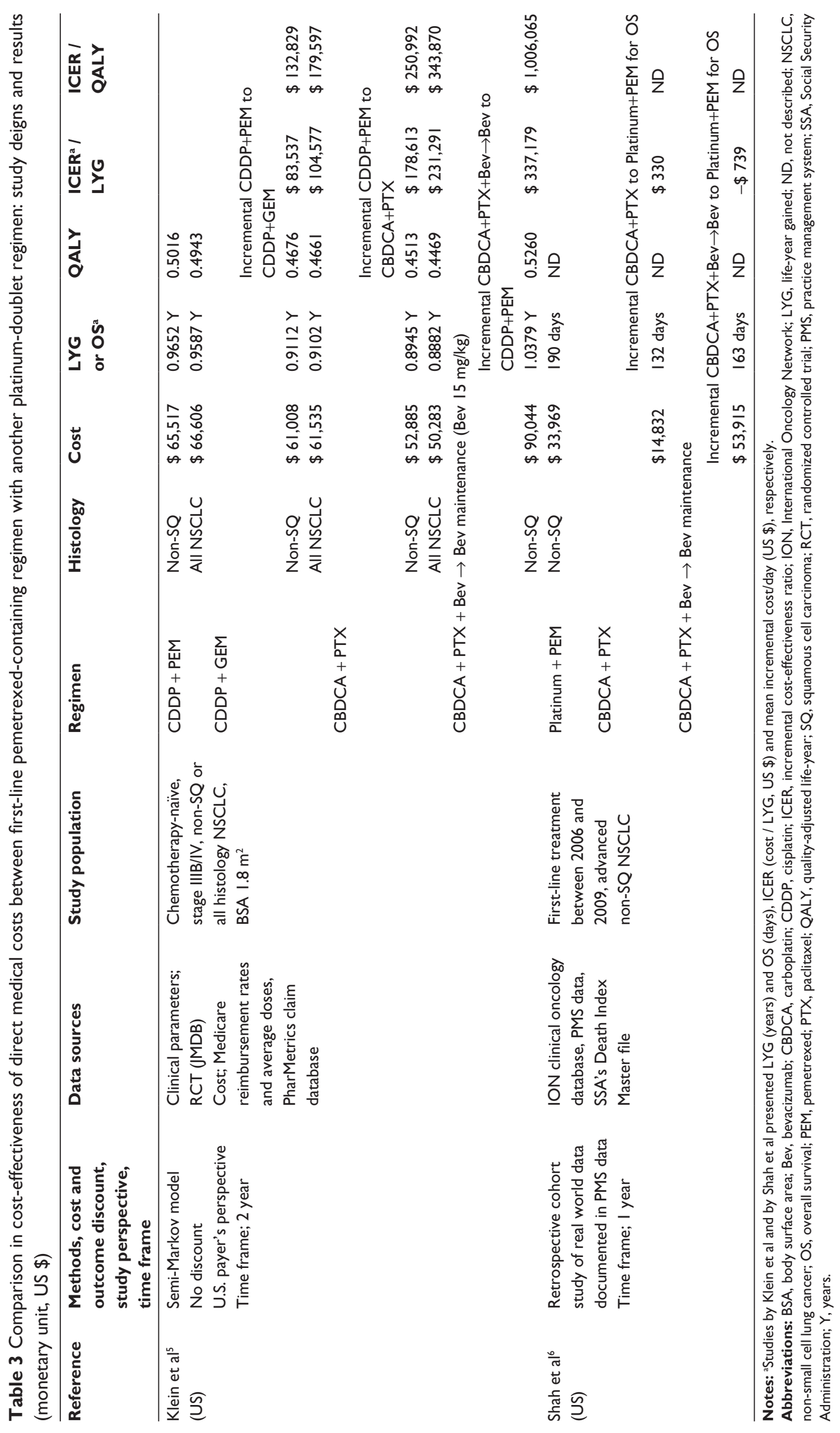


Currently, there are three drugs, comprising two molecular targeted drugs and one cytotoxic drug, approved as maintenance monotherapy after platinum-based induction chemotherapy: erlotinib (Tarceva ${ }^{\circledR}$, Hoffmann-La Roche Ltd, Basel, Switzerland), a reversible epidermal growth factor receptor (EGFR) tyrosine kinase inhibitor (TKI), as switch maintenance for patients with any NSCLC histology; bevacizumab (Avastin ${ }^{\circledR}$, Hoffmann-La Roche Ltd), a humanized monoclonal antibody that inhibits vascular endothelial growth factor and thereby angiogenesis, as continuation maintenance after platinum-based and bevacizumab-containing triplet induction for patients with non-squamous NSCLC; and pemetrexed as both types of maintenance for patients with non-squamous NSCLC.
Efficacy, safety, and tolerability of
pemetrexed maintenance therapy

Pemetrexed is the only successful cytotoxic drug in maintenance therapy. There are three cytotoxic drugs that have been tested as candidates of continuation maintenance in phase III trials, but they showed different results (Table 4). Paclitaxel improved neither PFS nor OS, ${ }^{11}$ gemcitabine prolonged only PFS but not OS, ${ }^{12-14}$ and only pemetrexed successfully extended both PFS and OS. ${ }^{15,16}$ In addition, severe adverse effects were less frequent during the pemetrexed maintenance phase, compared indirectly with paclitaxel and gemcitabine maintenance (Table 5). Thus, pemetrexed had an advantage of less cumulative toxicity and better tolerability.

Table 4 Phase III studies comparing a maintenance cytotoxic monotherapy with observation alone after induction chemotherapy

\begin{tabular}{|c|c|c|c|c|c|c|c|c|}
\hline Reference & PEP & $\mathbf{n}$ & Induction & Maintenance & $\begin{array}{l}\text { PFS or } \\
\text { TTP (M) }\end{array}$ & $\begin{array}{l}\text { HR } \\
P \text {-value }\end{array}$ & $\begin{array}{l}\text { OS } \\
\text { (M) }\end{array}$ & $\begin{array}{l}\text { HR } \\
P \text {-value }\end{array}$ \\
\hline \multicolumn{9}{|c|}{ Continuation maintenance } \\
\hline \multirow[t]{4}{*}{ Belani et al" } & $\mathrm{RR}$ & 401 enrolled & 3 regimens of & & & & & \\
\hline & TTP & I 30 randomized & CBDCA + PTX & \multicolumn{5}{|c|}{ Survival from randomization before induction chemotherapy } \\
\hline & & 65 & $\left(\operatorname{arm~I-3)^{\mathrm {a}}}\right.$ & w PTX & 8.9 & $P=0.124$ & 17.5 & $P=0.243$ \\
\hline & & 65 & & Obs & 6.8 & & 14.0 & \\
\hline Brodowicz et $\mathrm{al}^{13}$ & TTP & 352 induction & CDDP + GEM & & & & & \\
\hline \multirow[t]{7}{*}{ (CECOG trial) } & & 257 non-PD & $\times 4$ cycles & & & & & \\
\hline & & 215 randomized & & \multicolumn{5}{|c|}{ Survival from first treatment administration } \\
\hline & & 138 & & GEM & 6.6 & HR ND & 13.0 & HR ND \\
\hline & & 68 & & Obs & 5.0 & $P<0.001$ & 11.0 & $P=0.195$ \\
\hline & & & & \multicolumn{5}{|c|}{ Survival from randomization after induction chemotherapy } \\
\hline & & 138 & & GEM & 3.6 & HR ND & 10.2 & HR ND \\
\hline & & 68 & & Obs & 2.0 & $P<0.001$ & 8.1 & $P=0.172$ \\
\hline \multirow[t]{4}{*}{ Belani et al ${ }^{\prime 2}$} & OS & 519 enrolled & CBDCA + GEM & & & & & \\
\hline & & 255 randomized & $\times 4$ cycles & \multicolumn{5}{|c|}{ Probably from randomization after induction chemotherapy } \\
\hline & & 128 & & GEM & 3.9 & HR ND & 8.0 & HR 0.97 \\
\hline & & 127 & & Obs & 3.8 & $P$-value ND & 9.3 & $P=0.84$ \\
\hline Perol et $\mathrm{al}^{14}$ & PFS & 834 enrolled & CDDP + GEM & & & & & \\
\hline \multirow[t]{3}{*}{ (IFCT-GFPC0502 trial) } & & 464 randomized & $\times 4$ cycles & \multicolumn{5}{|c|}{ Survival from randomization after induction chemotherapy } \\
\hline & & 154 & & GEM & 3.8 & HR 0.56 & 12.1 & HR 0.89 \\
\hline & & 155 & & Obs & 1.9 & $P<0.001$ & 10.8 & $P=0.3867$ \\
\hline Paz-Ares et al $\left.\right|^{15,16}$ & PFS & 939 induction & CDDP + PEM & OS of randomly & signed patier & , from start of & Juction & \\
\hline \multirow[t]{6}{*}{ (PARAMOUNT trial) } & & 539 non-PD & $\times 4$ cycles & chemotherapy & & & & \\
\hline & & 359 & & PEM & & & 16.9 & HR 0.79 \\
\hline & & 180 & & Obs & & & 14.0 & $P=0.0191$ \\
\hline & & & & \multicolumn{5}{|c|}{ Survival from randomization after induction chemotherapy } \\
\hline & & 359 & & PEM & 4.4 & HR 0.60 & 13.9 & HR 0.78 \\
\hline & & 180 & & Obs & 2.8 & $P<0.00$ I & 11.0 & $P=0.0198$ \\
\hline \multicolumn{9}{|l|}{ Switch maintenance } \\
\hline Ciuleanu et a ${ }^{29}$ & PFS & & Plt-based regimens & \multicolumn{5}{|c|}{ Survival from randomization after induction chemotherapy } \\
\hline \multirow[t]{2}{*}{ (JMEN trial) } & & 441 & $\times 4$ cycles & PEM & 4.3 & HR 0.50 & 13.4 & HR 0.79 \\
\hline & & 222 & & Placebo & 2.6 & $P<0.000$ I & 10.6 & $P=0.012$ \\
\hline
\end{tabular}

Notes: a Arm I, CBDCA (AUC $6 \mathrm{mg} / \mathrm{mL} \cdot \mathrm{min}$, day I) plus PTX ( $100 \mathrm{mg} / \mathrm{m}^{2}$, days I, 8, and I5) every 4 weeks; arm 2, CBDCA (AUC $2 \mathrm{mg} / \mathrm{mL} \mathrm{min}$, days I, 8, and I5) plus PTX $\left(100 \mathrm{mg} / \mathrm{m}^{2}\right.$, days I, 8, and I5) every 4 weeks; arm 3, CBDCA (AUC $2 \mathrm{mg} / \mathrm{mL} \cdot \mathrm{min}$ ) plus PTX (150 mg/m² in cycle I and $100 \mathrm{mg} / \mathrm{m}^{2}$ in cycle 2) weekly for 6 of 8 weeks. Abbreviations: AUC, area under the curve; CDDP, cisplatin; GEM, gemcitabine; HR, hazard ratio; M, months; ND, not described; Obs, observation alone; OS, overall survival; PEP, primary endpoint; PD, progressive disease; PEM, pemetrexed; PFS, progression-free-survival; Plt, platinum; PTX, paclitaxel; RR, overall response rate; TTP, time to progressive disease; w PTX, weekly paclitaxel. 
Table 5 Comparison of grade 3-4 adverse events during monotherapy maintenance phase (incidence rate $\geq 1 \%$ in any study)

\begin{tabular}{|c|c|c|c|c|c|c|c|c|c|}
\hline \multirow{2}{*}{$\begin{array}{l}\text { Reference } \\
\mathbf{n}\end{array}$} & \multirow{2}{*}{$\begin{array}{l}\text { Brodowicz et al }\left.\right|^{13} \\
\text { (CECOG trial) } \\
\overline{138}\end{array}$} & \multicolumn{2}{|c|}{ Belani et $\mathrm{al}^{12}$} & \multicolumn{2}{|c|}{$\begin{array}{l}\text { Perol et } \text { al }^{14} \\
\text { (IFCT-GFPC0502 } \\
\text { trial) }\end{array}$} & \multicolumn{2}{|c|}{$\begin{array}{l}\text { Paz-Ares et al }{ }^{16} \\
\text { (PARAMOUNT } \\
\text { trial) }\end{array}$} & \multicolumn{2}{|c|}{$\begin{array}{l}\text { Ciuleanu } \\
\text { et } \mathrm{al}^{29} \\
\text { (JMEN trial) }\end{array}$} \\
\hline & & 128 & 127 & 154 & 155 & 359 & 180 & 441 & 222 \\
\hline Maintenance regimens & GEM & GEM & BSC & GEM & BSC & PEM & BSC & PEM & BSC \\
\hline \multicolumn{10}{|l|}{ Hematologic } \\
\hline Leukopenia (\%) & 2.3 & ND & ND & ND & ND & 2.2 & 0 & 2 & $<1$ \\
\hline Neutropenia (\%) & 14.9 & 13.3 & 1.6 & 20.8 & 0.6 & 5.8 & 0 & 3 & 0 \\
\hline Anemia (\%) & 2.6 & 9.4 & 2.4 & 2.6 & 0.6 & 6.4 & 0.6 & 3 & $<1$ \\
\hline Thrombocytopenia (\%) & 1.7 & 9.4 & 1.4 & 6.5 & 0 & 1.9 & 0 & ND & ND \\
\hline \multicolumn{10}{|l|}{ Non-hematologic } \\
\hline Fatigue (\%) & ND & 3.9 & 1.6 & ND & ND & 4.7 & 1.1 & 5 & $<1$ \\
\hline Alopecia (\%) & 4.3 & ND & ND & ND & ND & ND & ND & ND & ND \\
\hline $\begin{array}{l}\text { Deterioration of } \\
\text { general condition (\%) }\end{array}$ & ND & ND & ND & 3.2 & 3.9 & ND & ND & ND & ND \\
\hline Pneumonia (\%) & ND & ND & ND & 3.2 & 1.3 & ND & ND & ND & ND \\
\hline Anorexia (\%) & ND & ND & ND & 0.6 & 0.6 & 0.3 & 0 & 2 & 0 \\
\hline Asthenia (\%) & ND & ND & ND & 1.9 & 0 & ND & ND & ND & ND \\
\hline Febrile neutropenia (\%) & ND & ND & ND & ND & ND & 1.9 & 0 & ND & ND \\
\hline Infection (\%) & ND & ND & ND & 1.3 & 0 & ND & ND & 2 & 0 \\
\hline Pain (\%) & ND & ND & ND & ND & ND & 1.1 & 0 & ND & ND \\
\hline
\end{tabular}

Notes: Study by Brodowicz et al (CECOG trials) ${ }^{13}$ did not describe adverse events in the control arm. No study compared adverse events statistically.

Abbreviations: BSC, best supportive care; GEM, gemcitabine; ND, not described; PEM, pemetrexed.

Erlotinib switch maintenance has never been compared with pemetrexed switch or continuation maintenance in a head-to-head Phase III trial. Bevacizumab combined with carboplatin plus paclitaxel has been directly compared with pemetrexed continuation maintenance in two Phase
III studies (Table 6). ${ }^{17,18}$ These two studies, PRONOUNCE and ERACLE, defined unique primary endpoints of PFS without grade 4 adverse events ${ }^{18}$ and difference in QoL, ${ }^{17}$ respectively, instead of the usual efficacy parameters of PFS or OS. Thus, these studies provided little information with

Table 6 Phase III studies comparing bevacizumab with pemetrexed or pemetrexed plus bevacizumab

\begin{tabular}{|c|c|c|c|c|c|c|c|c|}
\hline Reference & PEP & $\mathbf{n}$ & Induction & Maintenance & $\begin{array}{l}\text { PFS } \\
\text { (M) }\end{array}$ & $\begin{array}{l}\text { HR } \\
P \text {-value }\end{array}$ & $\begin{array}{l}\text { OS } \\
(\mathrm{M})\end{array}$ & $\begin{array}{l}\text { HR } \\
P \text {-value }\end{array}$ \\
\hline Zinner et al ${ }^{18}$ & G4PFS & 361 & CBDCA + PEM & PEM & Surviv & m random & snment & \\
\hline \multirow[t]{7}{*}{ (PRONOUNCE trial) } & & & $\mathrm{CBDCA}+\mathrm{PTX}+\mathrm{Bev}$ & Bev & before & Iction chem & erapy & \\
\hline & & & $\times 6$ cycles & & G4PFS & & & \\
\hline & & 182 & & PEM & 3.9 & HR 0.85 & 10.5 & HR I.07 \\
\hline & & 179 & & Bev & 2.9 & $P=0.176$ & 11.7 & $P=0.615$ \\
\hline & & & & & PFS & & & \\
\hline & & 182 & & PEM & 4.4 & HR I.06 & & \\
\hline & & 179 & & Bev & 5.5 & $P=0.6 \mathrm{I}$ & & \\
\hline Galetta et $\mathrm{al}^{17}$ & QoL ${ }^{a}$ & 118 & & & & & & \\
\hline \multirow[t]{2}{*}{ (ERACLE trial) } & & 60 & CDDP + PEM & PEM & ND & HR 0.62 & ND & HR 0.69 \\
\hline & & 58 & $\begin{array}{l}\text { CBDCA }+ \text { PTX }+ \text { Bev } \\
\times 6 \text { cycles }\end{array}$ & Bev & ND & $P=0.03$ & ND & $P=0.08$ \\
\hline Barlesi et $\mathrm{a}^{34,35}$ & PFS & 376 induction & CDDP + PEM + Bev & & & & & \\
\hline \multirow[t]{3}{*}{ (AVAPERL trial) } & & 253 non-PD & $\times 4$ cycles & \multicolumn{5}{|c|}{ Survival from random assignment after induction chemotherapy } \\
\hline & & 128 & & $\mathrm{PEM}+\mathrm{Bev}$ & 7.4 & HR 0.57 & 17.1 & HR 0.87 \\
\hline & & 125 & & Bev & 3.7 & $P<0.000$ I & 13.2 & $P=0.29$ \\
\hline Patel et $\mathrm{al}^{36}$ & OS & & & & & & & \\
\hline \multirow[t]{3}{*}{ (PointBreak trial) } & & 934 randomized & & Survival from ra & m assi & nt before in & tion tre & ment \\
\hline & & 472 & $\mathrm{CBDCA}+\mathrm{PEM}+\mathrm{Bev}$ & $\mathrm{PEM}+\mathrm{Bev}$ & 6.0 & HR 0.83 & 12.6 & HR 1.00 \\
\hline & & 467 & $\begin{array}{l}\text { CBDCA + PTX }+ \text { Bev } \\
\times 4 \text { cycles }\end{array}$ & Bev & 5.6 & $P=0.012$ & 13.4 & $P=0.949$ \\
\hline
\end{tabular}

Note: ${ }^{a} E Q 5 D$ Index (EQ5D-I) and EQ5D-VAS (Euro-QoL questionnaire) at 12 weeks during maintenance therapy.

Abbreviations: Bev, bevacizumab; CBDCA, carboplatin; CDDP, cisplatin; G4PFS, progression-free survival without grade 4 adverse event; HR, hazard ratio; M, months; ND, not described; OS, overall survival; PD, progressive disease; PEM, pemetrexed; PEP, primary endpoint; PFS, progression-free survival; PTX, paclitaxel; QoL, quality of life. 
regard to deciding which regimen is superior as the first-line regimen for patients with non-squamous NSCLC.

\section{Cost-effectiveness of pemetrexed maintenance therapy}

The cost-effectiveness of maintenance treatment with pemetrexed monotherapy is debatable (Table 7). There were five pharmacoeconomic analyses from various countries addressing this problem. ${ }^{19-23}$ Four analyses were based on a switch maintenance trial (JMEN), ${ }^{19-22}$ while the other was a continuation maintenance trial (PARAMOUNT). ${ }^{23}$ Three of these analyses concluded that pemetrexed maintenance is not cost-effective, irrespective of switch and continuation. ${ }^{21-23}$ In the pharmacoeconomic analyses from Japan, Switzerland, and the People's Republic of China, each willingness-to-pay threshold was assumed as $¥ 5-6$ million per LYG (US \$43,478-52,174 per LYG), ${ }^{22} € 72,000$ per QALY gained (Swiss federal court decision, November 23, 2010), ${ }^{21}$ and US \$13,527 per QALY gained $\left(3 \times\right.$ the per capita gross domestic product), ${ }^{23}$ respectively. All ICERs based on LYG or QALY were more than these thresholds. ${ }^{21-23}$ The UK analysis also found that the most plausible ICER was $£ 47,000$ per QALY gained, which was above the standard NICE willingness-to-pay range (£20,000 to $£ 30,000$ per QALY). ${ }^{19}$ Considering that maintenance treatment with pemetrexed fulfilled the end-of-life criteria, NICE in the UK optionally recommended switch maintenance by pemetrexed only for patients with non-squamous histology. ${ }^{24}$ In contrast, NICE did not recommend continuation maintenance by pemetrexed because the most plausible ICER, approximately $£ 74,500$ per QALY gained, was higher than that normally considered to be cost-effective, even if the supplementary advice of NICE on end-of-life treatments was taken into consideration. ${ }^{25}$ The US analysis indicated that pemetrexed may be considered cost-effective. ${ }^{20}$ The ICER for pemetrexed to observation alone, ie, US \$122,371, may not be cost-effective when compared with a commonly mentioned threshold of US $\$ 100,000$ per LYG, but may be cost-effective when compared with a range of US $\$ 95,000$ to US $\$ 264,000$ per LYG, a recently revised plausible lower and upper bounds for cost-effectiveness decision rule in the USA. ${ }^{26}$

Comparison of cost-effectiveness between different types of maintenance is more difficult because of a lack of head-tohead clinical trials. Three studies have indirectly compared direct medical costs between maintenance with pemetrexed and maintenance with another drug (Table 8). ${ }^{20,27,28}$ A US study showed that pemetrexed maintenance is more costeffective for patients with non-squamous NSCLC than erlotinib, because the ICER for pemetrexed versus erlotinib (US \$150,260/LYG) is within the acceptable range of willingness to pay. ${ }^{20}$ Another UK study also showed a clear advantage in favor of pemetrexed, ICER for erlotinib versus pemetrexed, £84,029/QALY gained. ${ }^{27}$ In contrast, a European cross-market cost comparison showed that total monthly treatment costs per patient, including acquisition costs, administration costs, and costs of treating adverse events, were more reasonable for erlotinib than for pemetrexed, ie, $€ 2,140$ for erlotinib versus $€ 3,453$ for pemetrexed in France, $€ 2,732$ versus $€ 5,534$ in Germany, $€ 1,518$ versus $€ 2,921$ in Italy, and €2,048 versus $€ 3,164$ in Spain. ${ }^{28}$ Thus, it remains unknown which maintenance strategy is the most cost-effective.

There were many study limitations in these pharmacoeconomic analyses; for example, a lack of clinical trials and detailed information about quality of life, imbalanced accrual in trials, and a variety of medical services among countries and territories. A Japanese study of direct medical cost by Tsuchiya et $\mathrm{al}^{22}$ was based on clinical results of JMEN study ${ }^{29}$ and Japanese health care system. Although the JMEN study included $32 \%$ of Asian population in pemetrexed switch maintenance group mainly from the People's Republic of China and Korea, no Japanese patient participated in this trial. The PARAMOUNT trial, undertaken in 93 center in 16 countries, included Asian population in only $4 \%$ of all cases. ${ }^{30}$ Therefore, we Japanese and Asian can not refer to clinical results of this trial for a pharmacoeconomic study. There were three Japanese single-arm, Phase II studies evaluating a combination of carboplatin plus pemetrexed followed by pemetrexed maintenance for patients with non-squamous NSCLC. These trials provided an impressive median OS of more than 20 months not only from maintenance chemotherapy in patients who had received maintenance therapy ${ }^{31,32}$ but also from induction chemotherapy in all enrolled patients. ${ }^{32,33}$ In contrast, the JMEN and PARAMOUNT studies showed a median OS of 16.5 and 16.9 months, respectively, from induction chemotherapy for patients who had proceeded into the maintenance phase (Table 9). ${ }^{15,16,29}$ OS in the Japanese single-arm, Phase II studies was much longer (by approximately 4 months) than in the multinational randomized placebo-controlled studies. Thus, the Japanese medical economic study possibly underestimated pemetrexed maintenance when based on clinical data from other ethnic groups and countries. Further studies and discussions are warranted with regard to pemetrexed maintenance.

\section{Future directions}

A recent interesting challenge is doublet combination maintenance (Table 6). ${ }^{34-36}$ We may have to consider EGFR mutation 


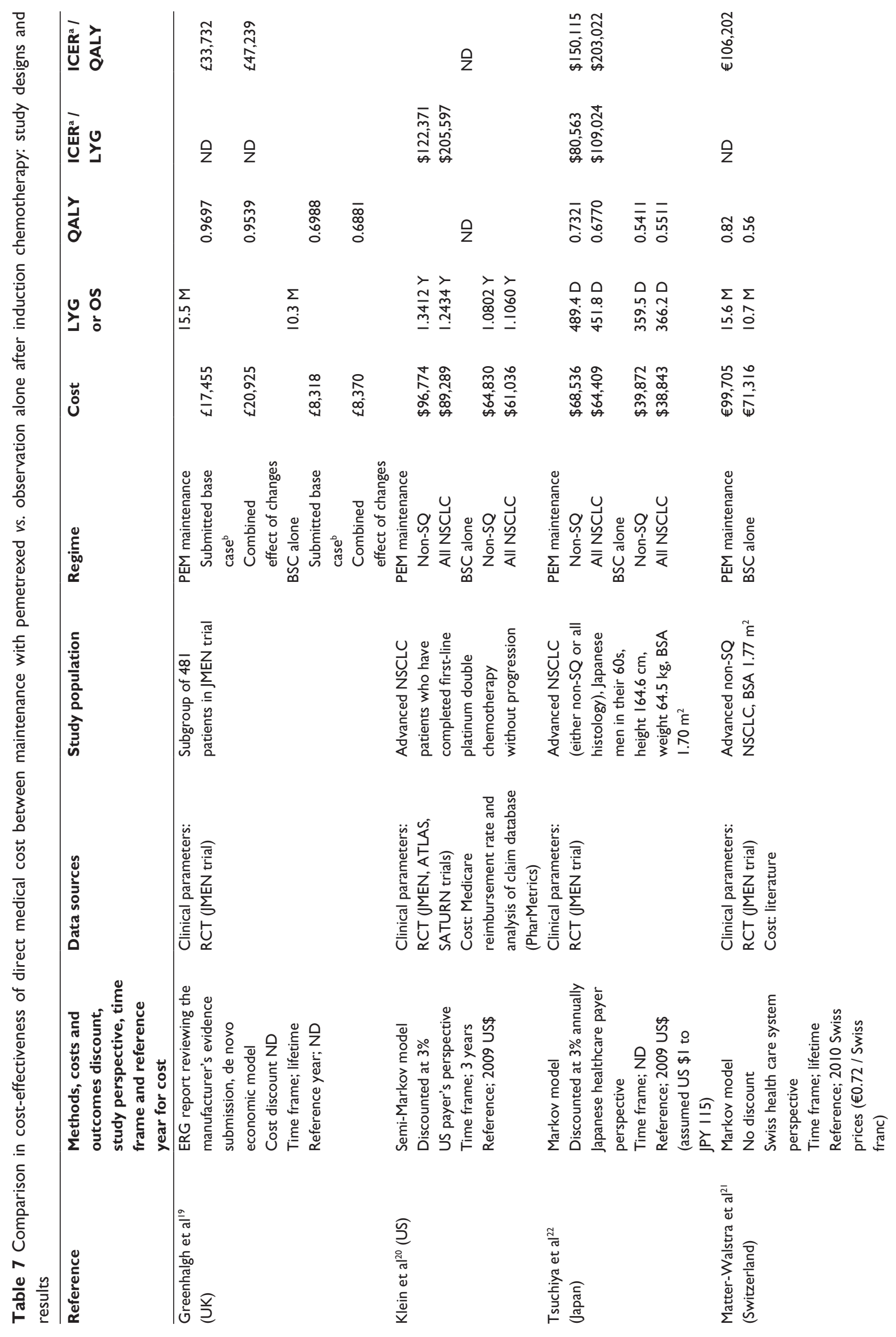




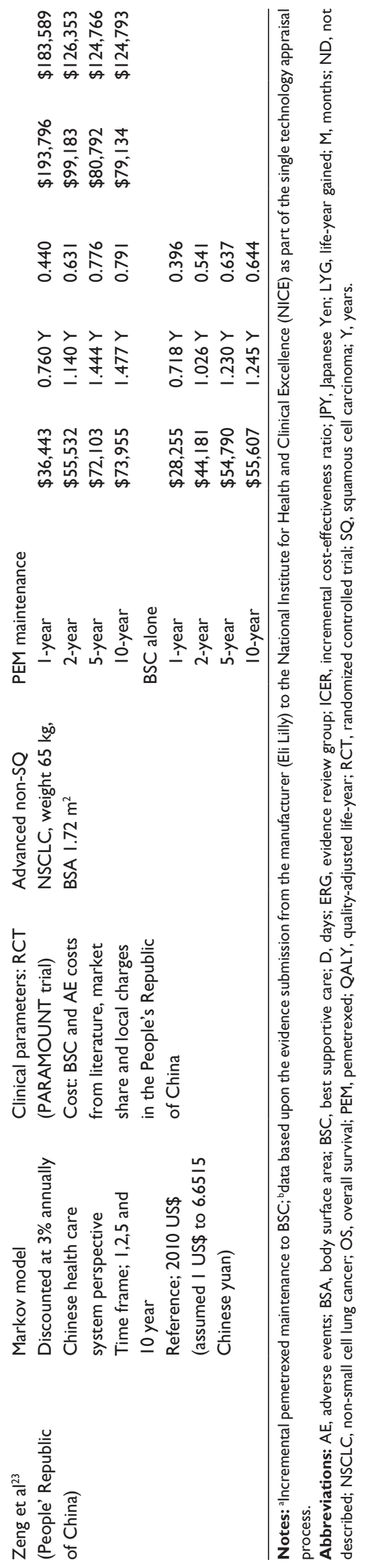

status for selection of a combination pattern. For patients with non-squamous NSCLC histology and positive EGFR mutation status, combination patterns of EGFR TKI with pemetrexed or bevacizumab are promising. A randomized Phase III trial is underway comparing gefitinib monotherapy with doublet continuation maintenance of pemetrexed plus gefitinib after triplet induction with carboplatin, pemetrexed, and gefitinib in patients with non-squamous NSCLC and positive EGFR mutations (NEJ009, trial number: UMIN000006340). This study potentially develops a first-line regimen for such patients. On the other hand, combination maintenance of bevacizumab plus an EGFR TKI is an alternative candidate treatment for these patients. Erlotinib provided an add-on effect with regard to PFS (bevacizumab plus placebo versus bevacizumab plus erlotinib; 3.7 versus 4.8 months from time of random assignment after induction chemotherapy, HR $0.71,95 \%$ CI $0.58-0.86, P<0.001)$, but failed in OS $(13.3$ versus 14.4 months, respectively, HR $0.92,95 \%$ CI $0.70-1.21$, $P=0.5341$ ), when a maintenance combination of erlotinib plus bevacizumab was introduced after four cycles of a bevacizumab-containing platinum-doublet chemotherapy for NSCLC patients who had not been selected by EGFR mutation status (ATLAS). ${ }^{37}$ For a subgroup with active EGFR mutations, compared with the wild-type subgroup, this combination maintenance therapy also achieved greater improvement in PFS (HR $0.44,95 \%$ CI $0.22-0.86$ for the EGFR mutationpositive subgroup [ $\mathrm{n}=52$ ] versus HR $0.85,95 \%$ CI $0.64-1.13$ for the EGFR wild-type subgroup [ $\mathrm{n}=295])$, but there was no statistically significant difference in OS outcome (HR 0.46, 95\% CI $0.21-1.02$ versus HR $0.86,95 \%$ CI $0.65-1.15$, respectively). Thus, for patients with wild-type EGFR and unknown EGFR mutation status, maintenance therapy of bevacizumab plus erlotinib is not recommended, while subgroup analyses of this randomized Phase III study suggested a potential efficacy of this maintenance combination for patients with active EGFR mutations. A recent randomized Phase II study in Japan (JO25567) also demonstrated that first-line bevacizumab plus erlotinib markedly improved PFS compared with erlotinib alone (16.0 months for erlotinib plus bevacizumab [n=77] versus 9.7 months for erlotinib alone [ $\mathrm{n}=77]$, HR 0.54 , 95\% CI $0.36-0.79, P=0.0015) .{ }^{38}$ This study suggests that, for patients with active EGFR mutation status, combination of these two molecularly targeted drugs potentially yields a better survival benefit than erlotinib alone. We hope that this combination is beneficial in the maintenance setting, as well as in the first-line setting.

For patients with non-squamous NSCLC and wild-type or unknown EGFR mutation status, pemetrexed plus bevacizumab 


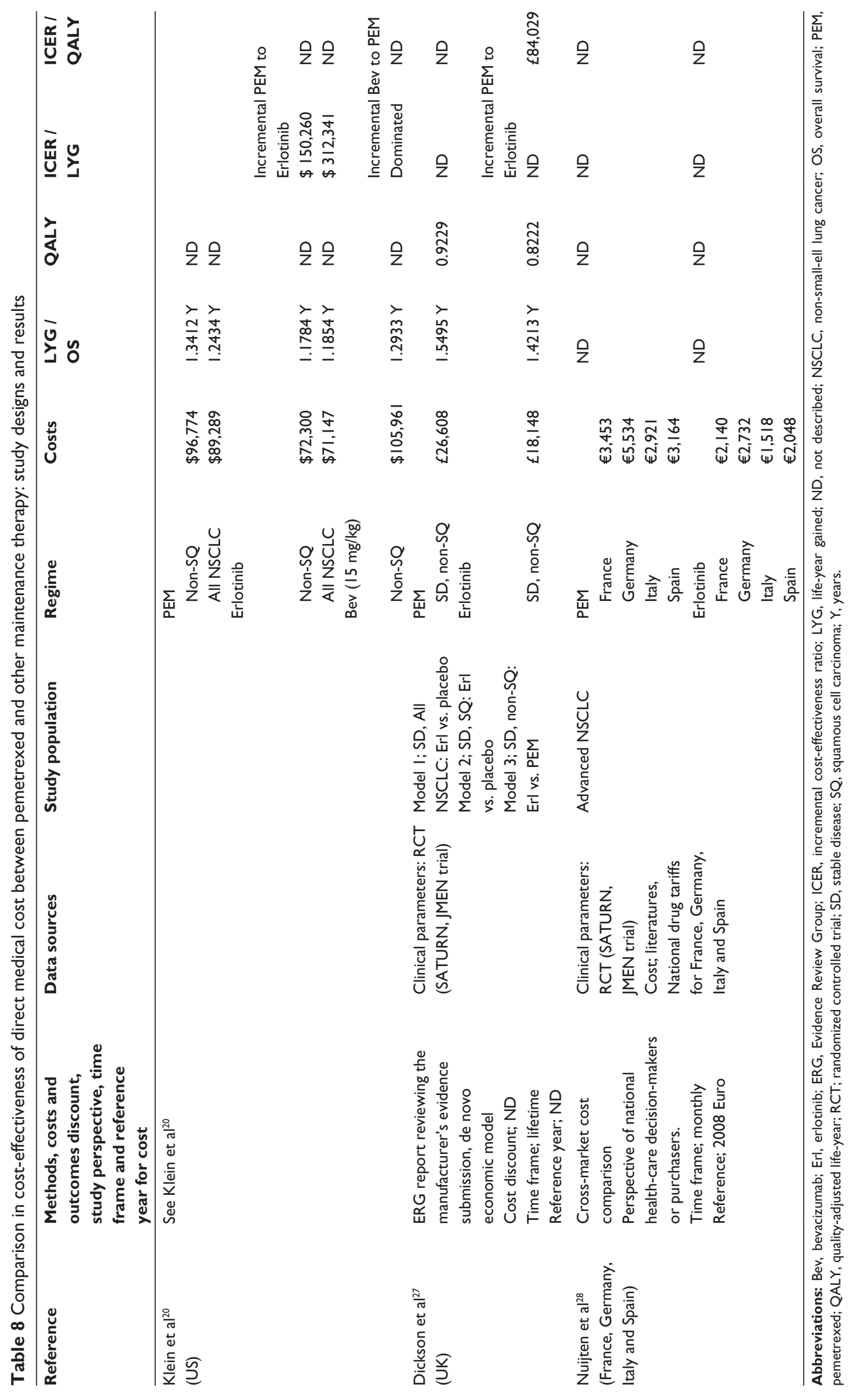


Table 9 Comparison of efficacy of the first-line combination of pemetrexed plus platinum followed by pemetrexed maintenance between Japanese Phase II studies and multinational Phase III studies

\begin{tabular}{|c|c|c|c|c|c|}
\hline Reference & Country & Phase & Patients & Treatment & $\begin{array}{l}\text { PFS and OS } \\
\text { from induction (M) }\end{array}$ \\
\hline $\begin{array}{l}\text { Ciuleanu et } \mathrm{a}^{29} \\
\text { (JMEN trial) }\end{array}$ & Multi & R-p3 & $\begin{array}{l}\text { 44I NSCLC, } \\
\text { including 26\% SQ }\end{array}$ & $\begin{array}{l}\text { Plt-based doublet } \times 4 \text { cycles } \\
\rightarrow \text { PEM maintenance }\end{array}$ & $\begin{array}{l}\text { PFS } 7.7 \\
\text { OS } 16.5\end{array}$ \\
\hline $\begin{array}{l}\text { Paz-Ares et al }{ }^{15,16} \\
\text { (PARAMOUNT trial) }\end{array}$ & Multi & R-p3 & 359 non-SQ & $\begin{array}{l}\text { CDDP }+ \text { PEM } \times 4 \text { cycles } \\
\rightarrow \text { PEM maintenance }\end{array}$ & $\begin{array}{l}\text { PFS ND } \\
\text { OS } 16.9\end{array}$ \\
\hline $\begin{array}{l}\text { Okamoto et } a^{33} \\
\text { (JACAL trial) }\end{array}$ & Japan & S-p2 & 109 non-SQ & $\begin{array}{l}\text { CBDCA }+ \text { PEM } \times 4 \text { cycles } \\
\rightarrow \text { PEM maintenance }\end{array}$ & $\begin{array}{l}\text { PFS } 5.7 \\
\text { OS } 20.2\end{array}$ \\
\hline $\begin{array}{l}\text { Minami et } \mathrm{a}^{32} \\
\text { (OULCSG0902 trial) }\end{array}$ & Japan & S-p2 & 34 non-SQ & $\begin{array}{l}\mathrm{CBDCA}+\mathrm{PEM} \times 4 \text { cycles } \\
\rightarrow \mathrm{PEM} \text { maintenance }\end{array}$ & $\begin{array}{l}\text { PFS } 5.2 \\
\text { OS } 23.3\end{array}$ \\
\hline Karayama et $\mathrm{a}^{31}$ & Japan & R-p2 & 26 non-SQ & $\begin{array}{l}\mathrm{CBDCA}+\mathrm{PEM} \times 4 \text { cycles } \\
\rightarrow \mathrm{PEM} \text { maintenance }\end{array}$ & $\begin{array}{l}\text { PFS } 7.4 \\
\text { OS } 25.0\end{array}$ \\
\hline
\end{tabular}

Abbreviations: CBDCA, carboplatin; CDDP, cisplatin; M, month; Multi, multinational; ND, not described; NSCLC, non-small-cell lung cancer; OS, overall survival; PEM, pemetrexed; PFS, progression-free survival; Plt, platinum; R-p2, randomized phase II; R-p3, randomized phase III; S-p2, single-arm phase II; SQ, squamous cell carcinoma.

is possibly promising. Compared with bevacizumab alone, continuation maintenance of pemetrexed plus bevacizumab significantly prolonged PFS by a median of 3.7 months, but did not achieve a significant improvement in OS, despite a difference of 3.9 months in median OS after four cycles of bevacizumab combined with cisplatin plus pemetrexed (AVAPERL). ${ }^{35}$ Another Phase III study (PointBreak) showed that continuation maintenance of pemetrexed plus bevacizumab after an induction triplet of bevacizumab combined with carboplatin plus pemetrexed was similar in OS but significantly superior in PFS when compared with continuation

Table 10 Comparison of grade 3-4 adverse events during maintenance phase (incidence rate $\geq 1 \%$ in any study)

\begin{tabular}{|c|c|c|c|c|}
\hline \multirow{2}{*}{$\begin{array}{l}\text { Reference } \\
\mathbf{n}\end{array}$} & \multicolumn{2}{|c|}{$\begin{array}{l}\text { Barlesi et } \text { al }^{34,35} \\
\text { (AVAPERL } \\
\text { trial) }\end{array}$} & \multicolumn{2}{|c|}{$\begin{array}{l}\text { Patel et } \text { al }^{36} \\
\text { (PointBreak } \\
\text { trial) }\end{array}$} \\
\hline & 125 & 120 & 292 & 298 \\
\hline Maintenance regimen & PEM + Bev & Bev & PEM + Bev & Bev \\
\hline \multicolumn{5}{|l|}{ Hematologic } \\
\hline Leukopenia (\%) & ND & ND & ND & ND \\
\hline Neutropenia (\%) & 5.6 & 0 & 14.0 & 11.4 \\
\hline Anemia (\%) & 3.2 & 0 & $11.0^{\mathrm{a}}$ & 0.3 \\
\hline Thrombocytopenia (\%) & 0 & 0 & $7.2^{\mathrm{a}}$ & 2.3 \\
\hline \multicolumn{5}{|l|}{ Non-hematologic } \\
\hline Fatigue (\%) & 2.4 & 1.7 & $9.6^{\mathrm{a}}$ & 1.7 \\
\hline Hypertension (\%) & 4.8 & 2.5 & 3.1 & 6.0 \\
\hline Sensory neuropathy (\%) & ND & ND & $0^{\mathrm{a}}$ & 4.7 \\
\hline Thromboembolic events (\%) & ND & ND & 2.4 & 0.7 \\
\hline Pulmonary embolism (\%) & 0.8 & 1.7 & ND & ND \\
\hline $\begin{array}{l}\text { Gl or pulmonary } \\
\text { hemorrhage }(\%)\end{array}$ & ND & ND & 1.4 & 0 \\
\hline Febrile neutropenia (\%) & 0.8 & 0 & 1.0 & 0 \\
\hline
\end{tabular}

Notes: AVAPERL study did not describe the result of statistical comparison. aStatistically significant $(P<0.05)$.

Abbreviations: Bev, bevacizumab; GI, gastrointestinal; ND, not described; PEM, pemetrexed. maintenance of bevacizumab alone after bevacizumab combined with carboplatin plus paclitaxel..$^{36}$ Thus, even the combination of pemetrexed plus bevacizumab remains unable to show an OS benefit when compared with bevacizumab alone. Adverse effects of anemia, thrombocytopenia, and fatigue were significantly more frequent on combination maintenance than on bevacizumab alone in the PointBreak trial (Table 10) ${ }^{36}$ Benefit in terms of cost-effectiveness should be investigated for these combination maintenance therapies when their significant survival benefits are demonstrated, because these drugs are all very expensive.

For the future, we may need to narrow the core patients who are predicted to benefit from maintenance therapy with pemetrexed or other drugs. Hence, more clear-cut markers are required, such as EGFR mutation status for NSCLC. The most promising predictive biomarker of the efficacy of pemetrexed at this time is the thymidylate synthase expression level. Basic research is warranted to identify a reliable biomarker than can predict the clinical benefit of pemetrexed. These personalized therapies represent appropriate treatment options and result in cost savings when using expensive drugs. Investigation of selection or exclusion biomarkers is warranted.

\section{Disclosure}

The authors report no conflicts of interest in this work.

\section{References}

1. World Health Organization. Cancer fact sheet 297. 2014. Available from: http://www.who.int/mediacentre/factsheets/fs297/en/. Accessed November 28, 2014.

2. Gronberg BH, Bremnes RM, Flotten O, et al. Phase III study by the Norwegian lung cancer study group: pemetrexed plus carboplatin compared with gemcitabine plus carboplatin as first-line chemotherapy in advanced non-small-cell lung cancer. J Clin Oncol. 2009;27(19):3217-3224. 
3. Rodrigues-Pereira J, Kim JH, Magallanes M, et al. A randomized phase 3 trial comparing pemetrexed/carboplatin and docetaxel/carboplatin as first-line treatment for advanced, nonsquamous non-small cell lung cancer. J Thorac Oncol. 2011;6(11):1907-1914.

4. Scagliotti GV, Parikh P, von Pawel J, et al. Phase III study comparing cisplatin plus gemcitabine with cisplatin plus pemetrexed in chemotherapy-naive patients with advanced-stage non-small-cell lung cancer. J Clin Oncol. 2008;26(21):3543-3551.

5. Klein R, Muehlenbein C, Liepa AM, Babineaux S, Wielage R, Schwartzberg L. Cost-effectiveness of pemetrexed plus cisplatin as first-line therapy for advanced nonsquamous non-small cell lung cancer. J Thorac Oncol. 2009;4(11):1404-1414.

6. Shah M, Winfree KB, Peterson P, Gruschkus SK, Eaddy M, Green MR. Cost effectiveness of first-line pemetrexed plus platinum compared with other regimens in the treatment of patients with nonsquamous non-small cell lung cancer in the US outpatient setting. Lung Cancer. 2013;82(1):121-127.

7. National Institute for Health and Clinical Excellence. Pemetrexed for the first-line treatment of non-small-cell lung cancer (TA181). 2009. Available from: http://www.nice.org.uk/guidance/ta181. Accessed November 28, 2014.

8. Zhang X, Zang J, Xu J, et al. Maintenance therapy with continuous or switch strategy in advanced non-small cell lung cancer: a systematic review and meta-analysis. Chest. 2011;140(1):117-126.

9. Behera M, Owonikoko TK, Chen Z, et al. Single agent maintenance therapy for advanced stage non-small cell lung cancer: a meta-analysis. Lung Cancer. 2012;77(2):331-338.

10. Cai H, Lin Y, Li W, Li X. Maintenance treatment with different strategies in advanced non-small-cell lung cancer: a systematic review and meta-analysis. Clin Lung Cancer. 2013;14(4):333-341.

11. Belani CP, Barstis J, Perry MC, et al. Multicenter, randomized trial for stage IIIB or IV non-small-cell lung cancer using weekly paclitaxel and carboplatin followed by maintenance weekly paclitaxel or observation. J Clin Oncol. 2003;21(15):2933-2939.

12. Belani CP, Waterhouse DM, Ghazal H, et al. Phase III study of maintenance gemcitabine $(\mathrm{G})$ and best supportive care (BSC) versus BSC, following standard combination therapy with gemcitabine-carboplatin (G-Cb) for patients with advanced non-small cell lung cancer (NSCLC). J Clin Oncol. 2010;28 Suppl 15:Abstr 7506.

13. Brodowicz T, Krzakowski M, Zwitter M, et al. Cisplatin and gemcitabine first-line chemotherapy followed by maintenance gemcitabine or best supportive care in advanced non-small cell lung cancer: a phase III trial. Lung Cancer. 2006;52(2):155-163.

14. Perol M, Chouaid C, Perol D, et al. Randomized, phase III study of gemcitabine or erlotinib maintenance therapy versus observation, with predefined second-line treatment, after cisplatin-gemcitabine induction chemotherapy in advanced non-small-cell lung cancer. J Clin Oncol. 2012;30(28):3516-3524.

15. Paz-Ares L, de Marinis F, Dediu M, et al. Maintenance therapy with pemetrexed plus best supportive care versus placebo plus best supportive care after induction therapy with pemetrexed plus cisplatin for advanced non-squamous non-small-cell lung cancer (PARAMOUNT): a double-blind, phase 3, randomised controlled trial. Lancet Oncol. 2012;13(3):247-255.

16. Paz-Ares LG, de Marinis F, Dediu M, et al. PARAMOUNT: final overall survival results of the phase III study of maintenance pemetrexed versus placebo immediately after induction treatment with pemetrexed plus cisplatin for advanced nonsquamous non-small-cell lung cancer. $J$ Clin Oncol. 2013;31(23):2895-2902.

17. Galetta D, Pisconti S, Cinieri S, et al. First-line pemetrexed plus cisplatin followed by maintenance pemetrexed versus carboplatinpaclitaxel plus bevacizumab followed by maintenance bevacizumab (ERACLE) in advanced nonsquamous NSCLC: a quality-of-lifeoriented, multicenter randomized phase III trial of the GOIM (Gruppo Oncologico Italia Meridionale). J Clin Oncol. 2013;31 Suppl:Abstr 8071.
18. Zinner RG, Ross HJ, Weaver R, et al. Randomized, open-label, phase III study of pemetrexed plus carboplatin (PemC) followed by maintenance pemetrexed versus paclitaxel/carboplatin/bevacizumab (PCB) followed by maintenance bevacizumab in patients with advanced nonsquamous (NS) non-small cell lung cancer (NSCLC). J Clin Oncol. 2013; 31 Suppl:Abstr LBA8003.

19. Greenhalgh J, McLeod C, Bagust A, et al. Pemetrexed for the maintenance treatment of locally advanced or metastatic non-small cell lung cancer. Health Technol Assess. 2010;14 Suppl 2:33-39.

20. Klein R, Wielage R, Muehlenbein C, et al. Cost-effectiveness of pemetrexed as first-line maintenance therapy for advanced nonsquamous non-small cell lung cancer. J Thorac Oncol. 2010;5(8):1263-1272.

21. Matter-Walstra K, Joerger M, Kuhnel U, Szucs T, Pestalozzi B, Schwenkglenks M. Cost-effectiveness of maintenance pemetrexed in patients with advanced nonsquamous-cell lung cancer from the perspective of the Swiss health care system. Value Health. 2012;15(1):65-71.

22. Tsuchiya T, Fukuda T, Furuiye M, Kawabuchi K. Pharmacoeconomic analysis of consolidation therapy with pemetrexed after firstline chemotherapy for non-small cell lung cancer. Lung Cancer. 2011;74(3):521-528.

23. Zeng X, Peng L, Li J, et al. Cost-effectiveness of continuation maintenance pemetrexed after cisplatin and pemetrexed chemotherapy for advanced nonsquamous non-small-cell lung cancer: estimates from the perspective of the Chinese health care system. Clin Ther. 2013;35(1): 54-65.

24. National Institute for Health and Clinical Excellence. Pemetrexed for the maintenance treatment of non-small-cell lung cancer (TA190). 2010. Available from: http://www.nice.org.uk/guidance/ta190. Accessed November 28, 2014.

25. National Institute for Health and Clinical Excellence. Pemetrexed maintenance treatment following induction therapy with pemetrexed and cisplatin for non-squamous non-small-cell lung cancer (TA309). 2014. Available from: http://www.nice.org.uk/guidance/ta309. Accessed Novemeber 28, 2014.

26. Braithwaite RS, Meltzer DO, King JT Jr, Leslie D, Roberts MS. What does the value of modern medicine say about the $\$ 50,000$ per qualityadjusted life-year decision rule? Med Care. 2008;46(4):349-356.

27. Dickson R, Bagust A, Boland A, et al. Erlotinib monotherapy for the maintenance treatment of non-small cell lung cancer after previous platinum-containing chemotherapy: a NICE single technology appraisal. Pharmacoeconomics. 2011;29(12):1051-1062.

28. Nuijten MJ, de Castro Carpeno J, Chouaid C, et al. A cross-market cost comparison of erlotinib versus pemetrexed for first-line maintenance treatment of patients with locally advanced or metastatic non-small-cell lung cancer. Lung Cancer. 2012;76(3):465-471.

29. Ciuleanu T, Brodowicz T, Zielinski C, et al. Maintenance pemetrexed plus best supportive care versus placebo plus best supportive care for non-small-cell lung cancer: a randomised, double-blind, phase 3 study. Lancet. 2009;374(9699):1432-1440.

30. Paz-Ares LG, Biesma B, Heigener D, et al. Phase III, randomized, double-blind, placebo-controlled trial of gemcitabine/cisplatin alone or with sorafenib for the first-line treatment of advanced, nonsquamous non-small-cell lung cancer. J Clin Oncol. 2012;30(25):3084-3092.

31. Karayama M, Inui N, Kuroishi S, et al. Maintenance therapy with pemetrexed versus docetaxel after induction therapy with carboplatin and pemetrexed in chemotherapy-naive patients with advanced nonsquamous non-small-cell lung cancer: a randomized, phase II study. Cancer Chemother Pharmacol. 2013;72(2):445-452.

32. Minami S, Kijima T, Komuta K, et al. Phase II trial of pemetrexed continuation - maintenance after carboplatin-based induction in untreated non-squamous non-small cell lung cancer. Anticancer Res. 2013;33(12):5535-5542.

33. Okamoto I, Aoe K, Kato T, et al. Pemetrexed and carboplatin followed by pemetrexed maintenance therapy in chemo-naive patients with advanced nonsquamous non-small-cell lung cancer. Invest New Drugs. 2013;31(5):1275-1282. 
34. Barlesi F, Scherpereel A, Gorbunova V, et al. Maintenance bevacizumabpemetrexed after first-line cisplatin-pemetrexed-bevacizumab for advanced nonsquamous nonsmall-cell lung cancer: updated survival analysis of the AVAPERL (MO22089) randomized phase III trial. Ann Oncol. 2014;25(5):1044-1052.

35. Barlesi F, Scherpereel A, Rittmeyer A, et al. Randomized phase III trial of maintenance bevacizumab with or without pemetrexed after first-line induction with bevacizumab, cisplatin, and pemetrexed in advanced nonsquamous non-small-cell lung cancer: AVAPERL (MO22089). J Clin Oncol. 2013;31(24):3004-3011.

36. Patel JD, Socinski MA, Garon EB, et al. PointBreak: a randomized phase III study of pemetrexed plus carboplatin and bevacizumab followed by maintenance pemetrexed and bevacizumab versus paclitaxel plus carboplatin and bevacizumab followed by maintenance bevacizumab in patients with stage IIIB or IV nonsquamous non-small-cell lung cancer. J Clin Oncol. 2013;31(34):4349-4357.
37. Johnson BE, Kabbinavar F, Fehrenbacher L, et al. ATLAS: randomized, double-blind, placebo-controlled, phase IIIB trial comparing bevacizumab therapy with or without erlotinib, after completion of chemotherapy, with bevacizumab for first-line treatment of advanced non-small-cell lung cancer. J Clin Oncol. 2013;31(31):3926-3934.

38. Kato T, Seto T, Nishio M, et al. Erlotinib plus bevacizumab (EB) versus erlotinib alone (E) as first-line treatment for advanced EGFR mutation-positive nonsquamous non-small cell lung cancer (NSCLC): an open-label randomized trial. J Clin Oncol. 2014;32 Suppl 5:Abstr 8005 .

\section{Publish your work in this journal}

Lung Cancer: Targets and Therapy is an international, peer-reviewed, open access journal focusing on lung cancer research, identification of therapeutic targets and the optimal use of preventative and integrated treatment interventions to achieve improved outcomes, enhanced survival and quality of life for the cancer patient. Specific topics covered in the journal include: Epidemiology, detection and screening Cellular research and biomarkers; Identification of biotargets and agents with novel

\section{Dovepress}

mechanisms of action; Optimal clinical use of existing anticancer agents, including combination therapies; Radiation and surgery; Palliative care; Patient adherence, quality of life, satisfaction; Health economic evaluations. The manuscript management system is completely online and includes a very quick and fair peer-review system. Visit http://www.dovepress.com/testimonials.php to read real quotes from published authors. 